УДК. 621.314

\title{
ДИНАМИЧЕСКАЯ МОДЕЛЬ АКТИВНОГО ТРЕХФАЗНОГО ВЫПРЯМИТЕЛЯ С КОРРЕКЦИЕЙ КОЭФФИЦИЕНТА МОЩНОСТИ
}

\author{
О. А. Плахтий, аспирант
}

\section{ДИНАМІЧНА МОДЕЛЬ АКТИВНОГО ТРИФАЗНОГО ВИПРЯМЛЯЧА 3 КОРЕКЦІЕЮ КОЕФІЦЕНТА ПОТУЖНОСТІ}

\section{О. А. Плахтій, аспірант \\ DYNAMIC MODEL OF ACTIVE THREE PHASE RECTIFIER WITH POWER FACTOR CORRECTION}

\section{A.Plakhtiy, PhD student}

В статье представлена дискретная динамическая модель активного трехфазного выпрямителя с коррекцией коэффищиента мощности. Достоинством предложенной модели является возможность исследований влияния управляющий коммутационных функиий, реализуемых системой управления, на электродинамические процессы в преобразователе. Представлены результать исследований предложенной модели, выполненные в программном пакете Matlab.

Ключевые слова: трехфазный активный выпрямитель, коррекция коэффициента мошности, динамическая модель.

У статті представлена дискретна динамічна модель активного трифазного випрямляча з корекиією коефіиієнта потужності. Перевагою запропонованої моделі $\epsilon$ можливість дослідження впливу комутаційних функиій системи керування на електродинамічні прочеси в перетворювачі. Представлені результати дослідження запропонованої моделі, проведені в програмному пакеті MATLAB.

Ключові слова: трифазний активний випрямляч, корекція коефіцієнта потужності, динамічна модель.

The article presents the discrete dynamic model of a three-phase active rectifier with power factor correction. This type of converter allows implementation of following options: power factor correction, sinusoidal input current, eliminating harmonic in input current, regulation of the output voltage of the rectifier, energy recovery in the network. Analysis of electromagnetic processes requires creation of a dynamic model of the converter. The dynamic model allows analyzing steadystate and transient processes, obtaining static and dynamic characteristics of the rectifier. Switching power converters can be considered either as discrete elements of automatic control systems, either as a continuous linear element. However, worth noting that by its nature the PWM rectifier is a nonlinear discrete element and its consideration as a discrete dynamical system is more accurate approach. The advantage of the proposed discrete model is the ability to research the influence of control switching functions on the electrodynamic processes in the converter.

Key words: three-phase active boost rectifier, power factor correction, dynamic model.

\section{Введение}

Применяемые

выпрямительных агрегатов

составе тяговых подстанций постоянного тока диодные и тиристорные выпрямители не соответствуют требованиям международных стандартов IEC 61000-3, IEEE 519, EN 61000-3-2 электромагнитной совместимости в части эмиссии высших гармоник тока. Кроме этого данные выпрямительные установки не 
обеспечивают возможности реализации рекуперации энергии в питающую сеть, что снижает энергоэфективность данных преобразователей. Внедрение активных трехфазных выпрямителей $\mathrm{c}$ коррекцией коэффициента мощности (далее $\mathrm{ABH}$ ) позволит решить проблемы электромагнитной совместимости, повышения коэффициента мощности, а также реализации рекуперации энергии в питающую сеть $[1,2]$.

Анализ электромагнитных процессов, протекающие в $\mathrm{ABH}$, требует создания математической и динамической модели преобразователя. Математическая модель позволяет проводить анализ установившихся и переходных процессов, получения статических и динамических характеристик преобразователя, синтеза замкнутых систем автоматического регулирования, а также анализ устойчивости работы преобразователя и его системы управления.

\section{Анализ последних исследований}

При исследовании динамических свойств импульсные преобразователи энергии можно рассматривать либо как дискретные (импульсные) элементы систем автоматического регулирования (САР), либо как непрерывный линейный элемент САР. Известен подход сведения дискретных математических моделей преобразователей к эквивалентным непрерывным моделям [3, 4]. Данный подход основан на представлении силовой части преобразователя и его системы управления в виде непрерывных звеньев САР. Описание активного выпрямителя с коррекцией коэффициента мощности в виде линейного элемента САР приведено в ряде работ $[2,3]$. Однако стоить отметить, что по природе физических процессов, протекающих в AB, данный преобразователь является нелинейным дискретным элементом САР и рассмотрение его в виде дискретной динамической системы является более точным подходом. Это позволяет получить в модели наиболее близкое к реальности отображение протекающих в преобразователе переходных процессов, а также исследовать влияние коммутационных функций системы управления на работу преобразователя.

Целью данной статьи является описание результатов исследований представленной дискретной динамической модели активного трехфазного выпрямителя c коррекцией коэффициента мощности выполненных в пакете Matlab.

1. Математическая модель активного выпрямителя с коррекцией коэффициента мощности

Схема замещения исследуемого активного трехфазного выпрямителя представлена на рисунке 1. В состав данного преобразователя входит шесть полностью управляемый IGBT-ключей с параллельными диодами (VT1-VT6); три входных дросселя $\mathrm{La}, \mathrm{Lb}, \mathrm{Lc}$; выходной конденсатор C; три входных сопротивления $\mathrm{Ra}, \mathrm{Rb}, \mathrm{Rc}$ имитирующие активное сопротивление входных дросселей.

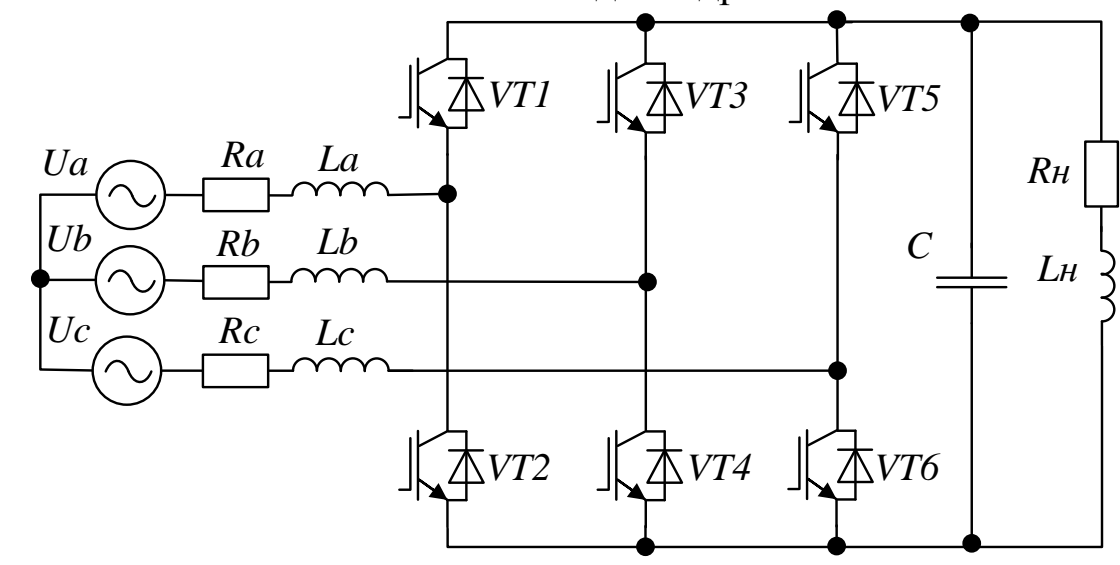

Рис. 1 - Схема замещения активного повышающего выпрямителя с коррекцией коэффициента мощности 
На данный момент существует показатели, а также коэффициент мощности несколько принципиально разных систем близкий к единице, как в режиме управления АВН. Автором предложена гистерезисная система управления, реализующая высокие энергетические выпрямления, так и в режиме рекуперации [4, 5]. Структурная схема предложенной системы управления приведена на рис. 2

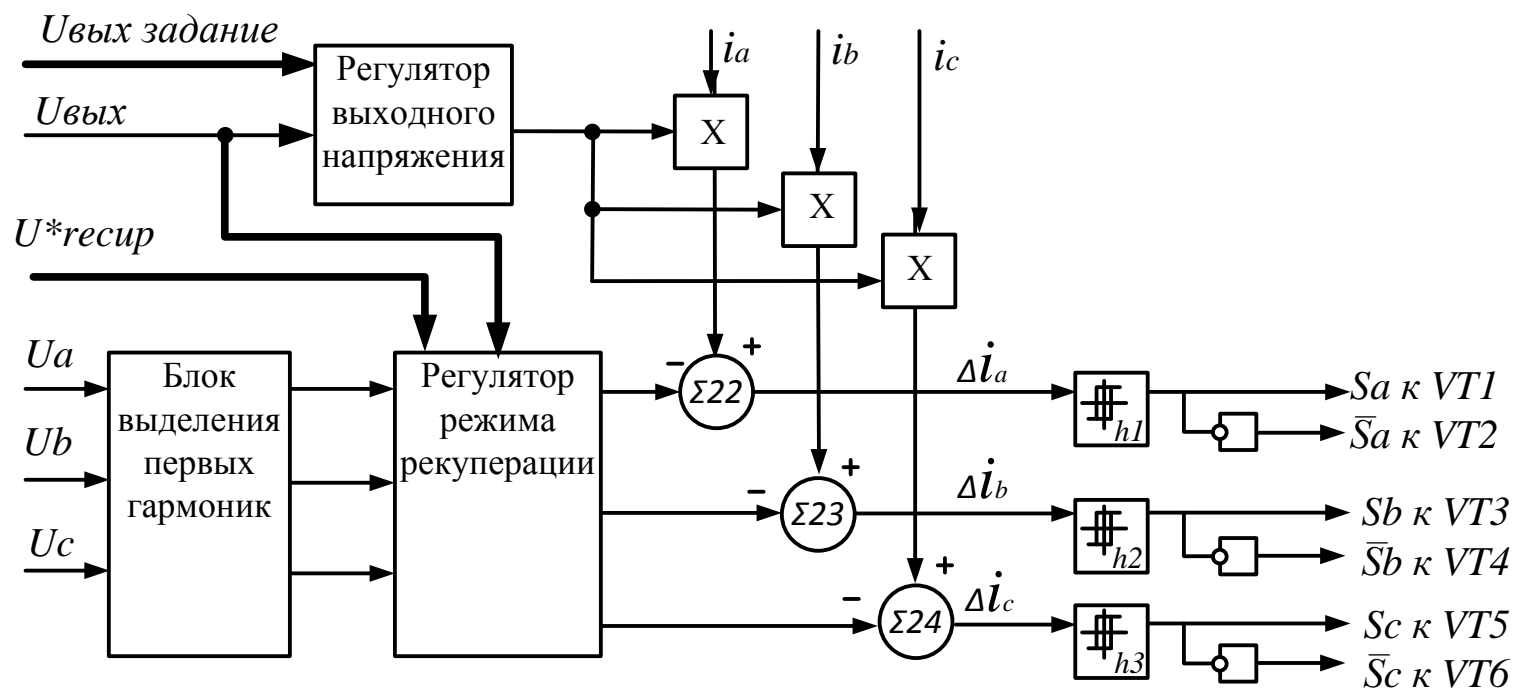

Рис.2 - Гистерезисная система управления активного трехфазного выпрямителя

Система управления формирует единице, то включен ключ анодной группы; управляющее воздействие на ключи АВН. а если КФ равно нулю, то включен ключ При этом вводится понятие коммутационных катодной группы. Коммутационные функций (далее КФ). Коммутационная состояния ключей активного выпрямителя функция описывает состояние ключей плеча приведены на рис.2. преобразователя. Если значение КФ равно
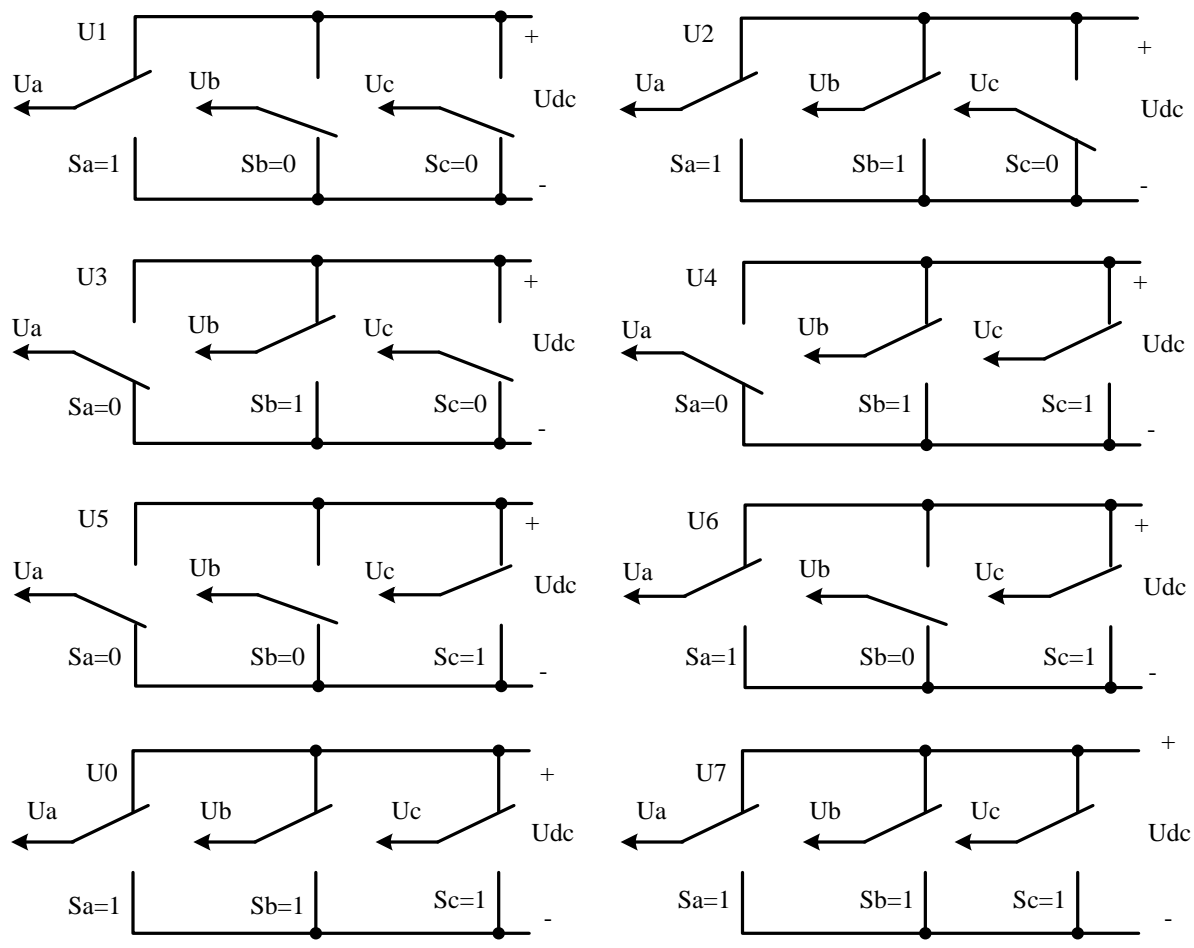

Рис. 2 - Коммутационные состояния ключей активного выпрямителя 
Векторная диаграмма коммутационных состояний ключей $\mathrm{ABH}$ приведення в $\alpha \beta$ системе координат представлена на рис. 3.

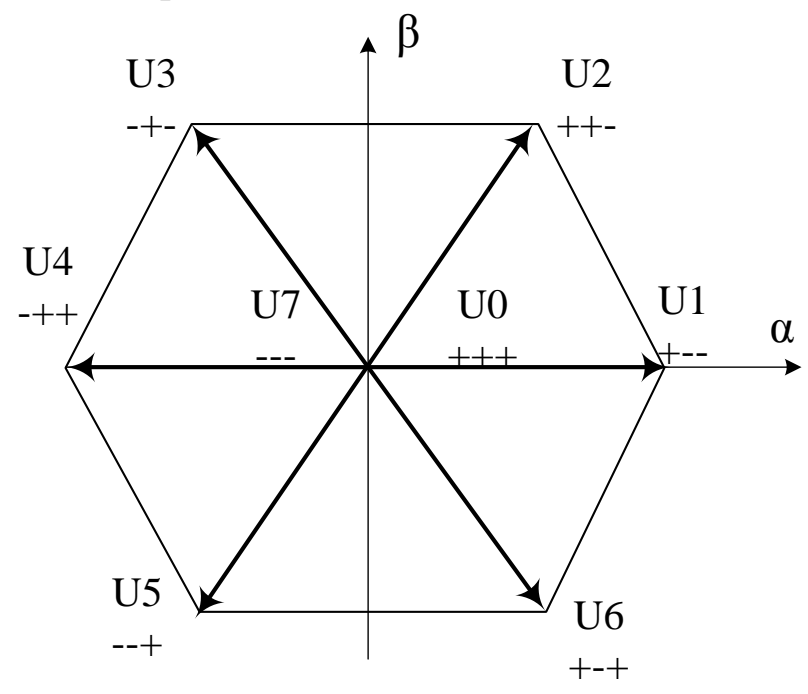

Рис. 3 - Векторная диаграмма напряжений АВН в $\alpha \beta$-системе координат

Исходя из коммутационных коммутационными функциями и линейными состояний ключем АBН, соотношение (межфазными) напряжениями, может быть выходного напряжения $\mathrm{ABH}$ с представлено в виде следующих уравнений:

$$
u_{D C}=\left\{\begin{array}{l}
\left(S_{A}-S_{B}\right) \cdot u_{A B} \\
\left(S_{B}-S_{C}\right) \cdot u_{B C} \\
\left(S_{C}-S_{A}\right) \cdot u_{C A}
\end{array}\right.
$$

При этом удобно связать значение фазных напряжений питания и напряжения в звене постоянного тока:

Где:

$$
u_{D C}=\left\{\begin{array}{l}
f_{a} \cdot u_{A N} \\
f_{b} \cdot u_{B N} \\
f_{c} \cdot u_{C N}
\end{array}\right.
$$

$$
\begin{aligned}
& f_{a}=\frac{2 S_{A}-\left(S_{B}+S_{C}\right)}{3} \\
& f_{b}=\frac{2 S_{B}-\left(S_{A}+S_{C}\right)}{3} \\
& f_{a}=\frac{2 S_{C}-\left(S_{A}+S_{B}\right)}{3}
\end{aligned}
$$

Переменные $f_{a}, f_{b}, f_{c}$ могут принимать значения $0, \pm 1 / 3, \pm 2 / 3$.

Система уравнений, описывающая баланс напряжений в преобразователе приведена в системе уравнений ниже.

$$
\left[\begin{array}{l}
u_{S a} \\
u_{S b} \\
u_{S c}
\end{array}\right]=R\left[\begin{array}{l}
i_{C a} \\
i_{C b} \\
i_{C c}
\end{array}\right]+L \frac{d}{d t}\left[\begin{array}{l}
i_{C a} \\
i_{C b} \\
i_{C c}
\end{array}\right]+\left[\begin{array}{l}
u_{C} \\
u_{C} \\
u_{C}
\end{array}\right]
$$

Дифференциальное описывающее зависимость напряжения от величины фазных токов с мгновенных значений коммутационных функций приведено ниже. 


$$
c \frac{d u_{d c}}{d t}=S_{a} i_{C a}+S_{b} i_{C b}+S_{c} i_{C c}-i_{d c}
$$

\section{Динамическая модель АВН}

Вышеприведенные уравнения (7-17) активного трехфазного выпрямителя можно преобразовать в динамическую модель, которая приведена на рисунке 4.

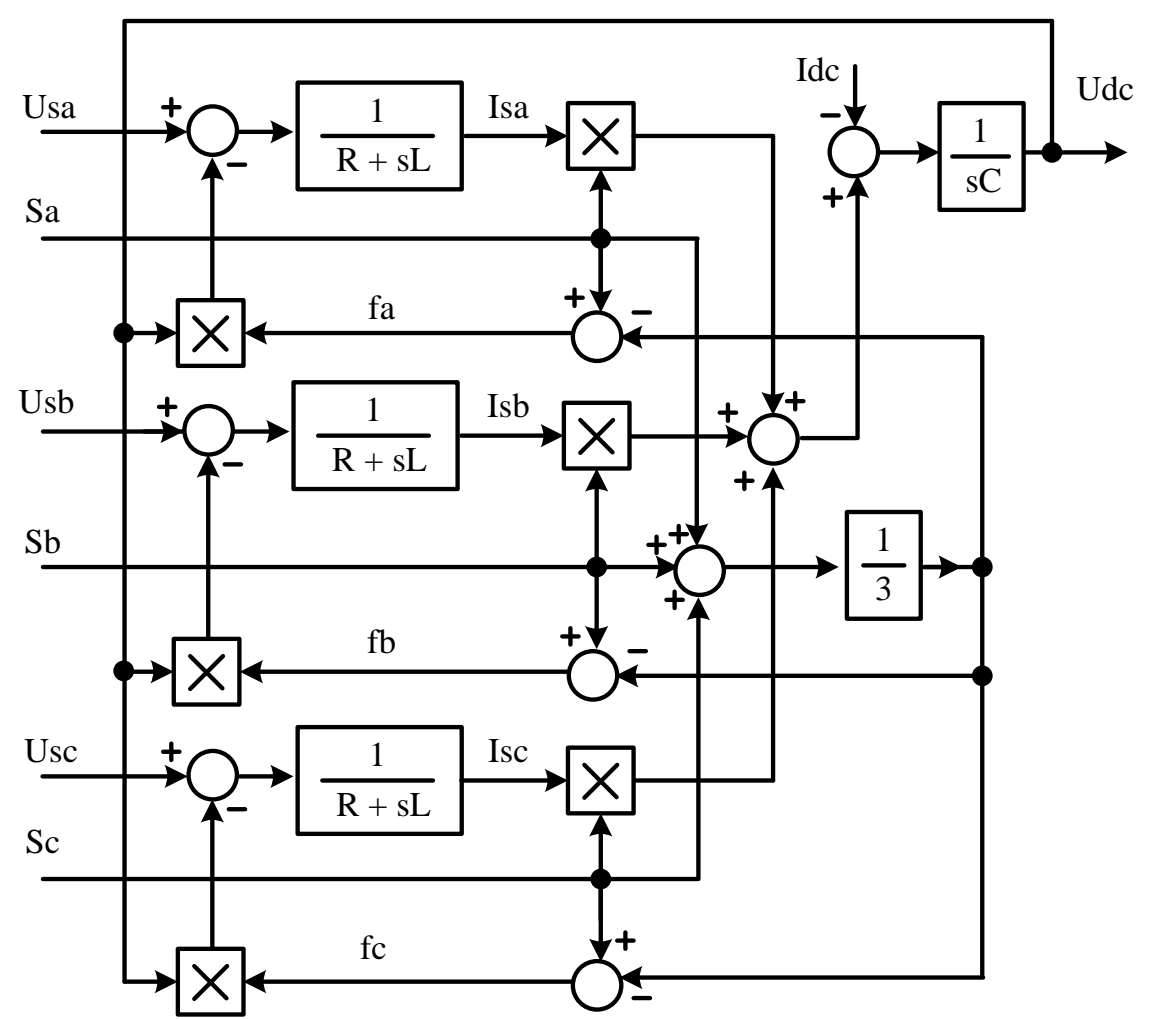

Рис. 4 -Динамическая модель активного трехфазного выпрямителя

B программе Matlab была создана Параметры модели: $\mathrm{La}=0,2 \mathrm{M} \Gamma \mathrm{H} ; \mathrm{Ra}=0,01 \mathrm{OM}$; дискретная динамическая модель $\mathrm{ABH} . \quad \mathrm{C}=6 \mathrm{M \kappa} \Phi ; \quad \mathrm{RH}=2 \quad \mathrm{Om} ; \quad \mathrm{LH}=20 \quad$ мГн.

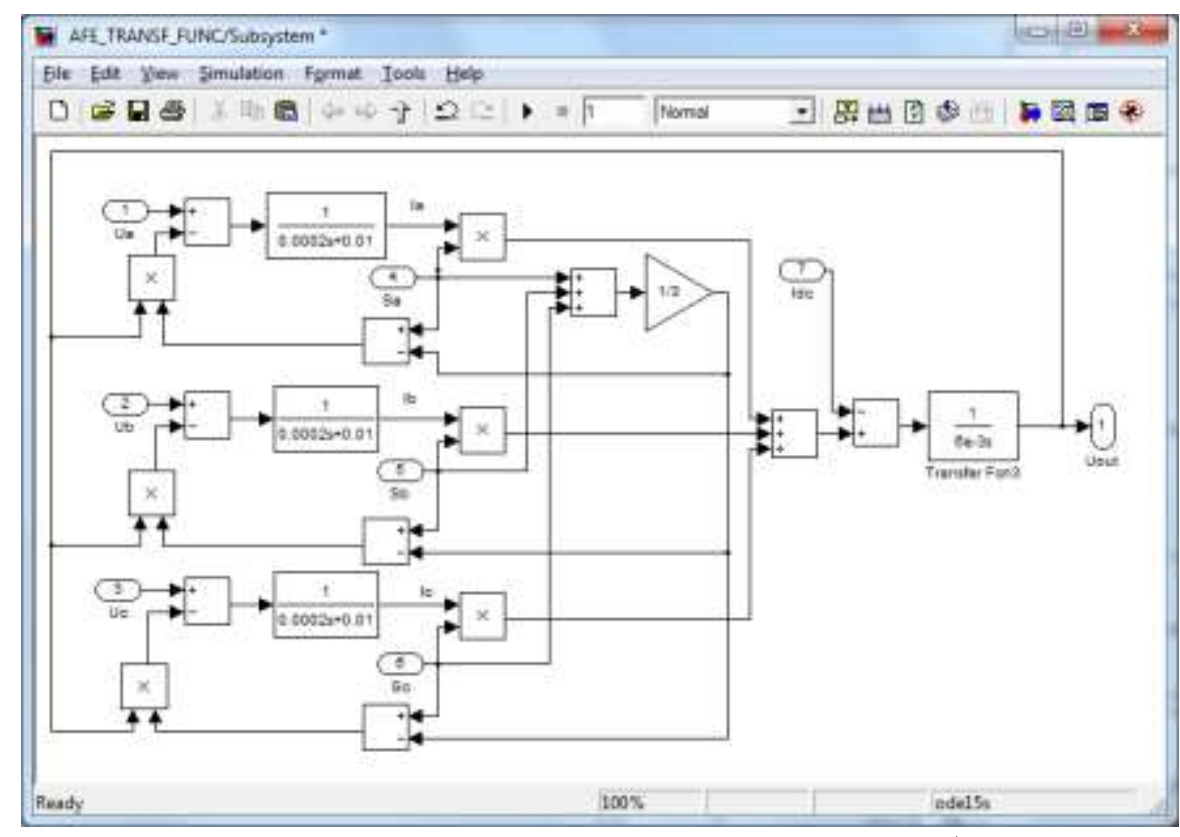

Рис. 5 -Дискретная динамическая модель АВН 
Автоматизовані системи електричного транспорту

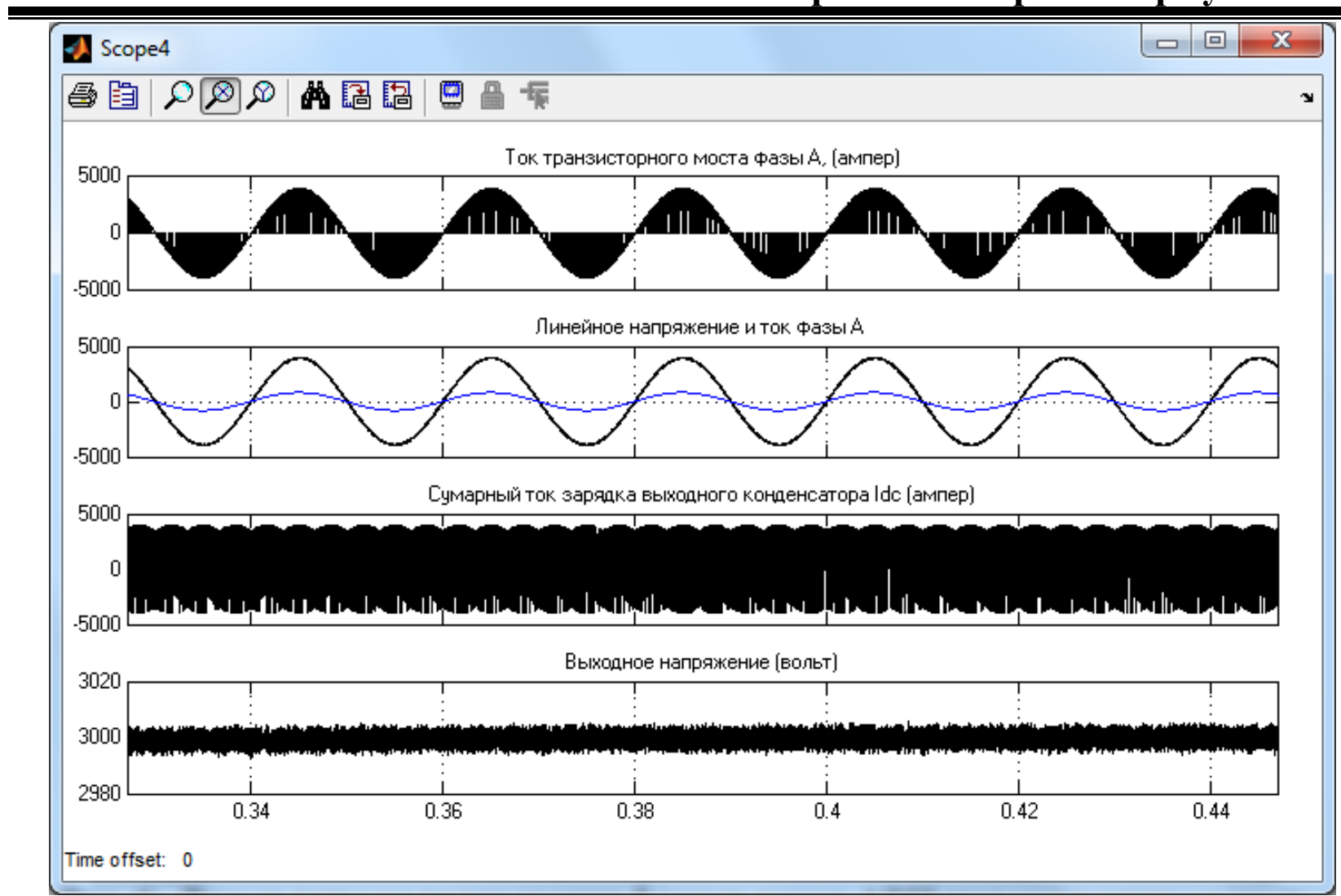

Рис. 6 -Результаты моделирования фазных токов АВН при математическом и имитационном моделировании

Из проведенного моделирования можно сделать следующие выводы:

$\begin{array}{ccr}- & \text { активный } & \text { выпрямитель } \\ \text { обеспечивает } & \text { коррекцию } & \text { коэффициента }\end{array}$ мощности в режиме выпрямления;

- амплитуда пульсаций выходного напряжения менее 10B.

\section{Выводы:}

В статье представлены исследования дискретной динамической модели активного трехфазного выпрямителя. Достоинством предложенной модели по сравнению с непрерывной моделью является то, что она учитывает коммутационные функции, полученные из системы управления. Адекватность модели подтверждено результатами имитационного моделирования.

Разработанная модель далее будет использована для анализа устойчивости активного выпрямителя, как элемента системы автоматического регулирования.

\section{Список литературы:}

1. Maswood A.I, A novel variable hysteresis band current control of three-phase threelevel rectifier with constant switching frequency [Текст], IEEE Power Engineering Society General Meeting, Vol. 1, Issue, 12-16 June 2005, C. 23- 27.

2. Казачковский Н.Н. Способ управления векторным релейным регулятором тока в электро- приводах с ШИМ [Текст] / Н.Н. Казачковский, Д.В. Якупов // Вісник Кременчуцького державного політехнічного університету: Наукові праці КДПУ. Кременчук: КДПУ, 2004. - Вип. 3/2004 (26). - С. 46-49.

3. Казачковский Н. Н. Управление активным выпрямителем с широтноимпульсной модуляцией при возмущениях со стороны нагрузки [Текст] / Н.Н. Казачковский., Д.В. Якупов // Вісник Приазовського державного технічного університету: 3б. наук. пр.- Маріуполь, - Вип. 18, 2008. -С. 40-43. 
4. Плахтий А.А. Гистерезисная система управления активного трехфазного выпрямителя с коррекцией коэффициента мощности [Текст] / // Зб. наук. праць НУК. Миколаїв: НУК, 2013: - Вип. 4. - С. 82-88.

5. Щербак Я.В. Исследование режима рекуперации активного трехфазного выпрямителя с коррекцией коэффициента мощности [Текст] / Я.В. Щербак, А.А. Плахтий // Зб. наук. праць УкрДАЗТ. - Харків: УкрДАЗТ, 2012: - Вип. 143. - С. 188-194.

Рецензент д-р техн. наук, профессор Я.В.Щербак

Плахтий Александр Андреевич, Аспирант кафедры автоматизированных систем электрического транспорта, Украинская государственная академия железнодорожного транспорта, Контактный телефон: +38 093 9176020, E-mail: 83et@ mail.ru

Plakhtiy Alexandr Andrievich, Phd. Student, Chair Automated control systems of railway transport, Ukrainian State Academy of railway transport, Contact phone: +38 093 9176020, E-mail: 83et@mail.ru

Плахтій Олександр Андрійович, Аспірант кафедри автоматизованих систем електричного транспорта, Українська державна академія залізничного транспорта, Контактний телефон: +38 093 9176020, E-mail: 83et@mail.ru

Стаття поступила 20.04.2015 